\title{
Cómo surge una villa en el siglo XVI: San Miguel de la Ribera y sus Ordenanzas municipales
}

\author{
por

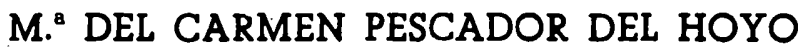 \\ Del Archivo Histórico Nacional
}

Entre los términos municipales de Fuentespreadas y de El Piñero, de Venialbo, Toro, Villamor y Argujillo se encontraba a mediados del siglo xvi un lugar cuyos vecinos, en número de ciento ochenta (1), se dedicaban principalmente a las labores del campo propias de las tierras de pan y vino, con un pequeño complemento de ganadería, pequeño porque la naturaleza del terreno, escaso de pastos y arbolado, hacía poner toda clase de vetos a la entrada de los ganados no sólo en las tierras de labranza, sino aun en los prados, llamados «sanjuaniegos» por estar prohibido su pasto desde primero de febrero a San Juan de junio (día 24), y lo mismo en el prado llamado de la Vega destinado a los bueyes, en el que se segaba hierba para bueyes y mulas. El monte era de mata baja y apenas empezado a formarse y contaba con algunos sotos escasamente poblados. En sus campos se cultivaba el trigo y la cebada, el centeno y la avena. Donde lo pedía el terreno melones y garbanzales. También viñas y las huertas indispensables en la vida de toda agrupación rural (2). Su extensión no era mucha: tres cuartos de legua de largo por media, poco más o menos, de ancho (3). En uno de los terrenos comunales había un manantial

(1) Relación de Hernando de Medina, en el Apéndice documental.

(2) Se legisla sobre todo esto en los artículos de las Ordenanzas.

(3) Relación de Hernando de Medina, en el Apéndice documental. 
de donde se surtía el vecindario (4). El nombre de este lugar era Aldea del Palo y formaba parte del grupo de las aldeas pertenecientes a la ciudad de Zamora.

Carlos I de España y V de Alemania: metido en empresas de amplitud universal, tenía que atender a múltiples problemas tanto en el terreno político como en el religioso, y para ello necesitaba mantener ejércitos que le acarreaban «muchos y grandes gastos de dineros» (5). No eran suficientes los socorros, ayudas, servicios ordinarios y extraordinarios, ni «lo que ha venido y verná de las Yndias», ni los ingresos de subsidio y bulas de Cruzada, ni el importe de la venta de algunas rentas y bienes de la Corona y Patrimonio real (6). Necesitaba más y por ello concibe la idea de poner en marcha nuevos recursos.

Durante sus largas y obligadas ausencias ejercía como Gobernadora su hija la Princesa Juana de Portugal y a ella otorga poder cumplido desde Betuna (Bethune), en el Paso de Calais, en primero de septiembre de 1554, para que los lleve a efecto. Contando con el disgusto que va a producir su decisión en muchos de sus súbditos, hace relación en el preámbulo de los motivos que tiene para tales medidas extraordinarias con lo que trata de justificarse. Comienza su relato notificando que el rey de Francia «siguiendo lo que acostumbra» le ha declarado la guerra, formando liga con el Turco, varios navios de Argel y algunos príncipes alemanes. Denuncia el plan de los enemigos de atacar los Estados de Flandes, pertenecientes a su patrimonio, para obligarle a desguarnecer el Imperio y poder entrar por Italia para apoderarse de Nápoles, del Estado de Milán y de lo que resta del Piamonte, aseguran-

(4) Artículo 12 de las Ordenanzas. Véase nota 22.

(5) Preámbulo de la cédula del Emperador incorporada en la carta de compra.

(6) Carta de ratificación de Felipe II incorporada en la carta de compra. Enumera: autorización para vender las rentas de la Corona y Patrimonio perpetuamente o alquitar, siempre que no fueren alcabalas; poder para administrar las tres Ordenes (Santiago, Calatrava y Alcántara) y para desmembrar y vender de ellas, sus maestrazgos y encomiendas lo que está autorizado por bulas y breves pontificios, compensándoles con privilegios de juro; vender alquitar vasallos, villas, lugares y fortalezas con todos sus derechos y pertenencias; desmembrar y vender (por bula de Julio III) vasallos de los monasterios de las Ordenes de San Benito, San Bernardo $y$ otras. 
do que piensan llevar la guerra no sólo a las costas de Sicilia, sino también a las de España. Después de estas razones pasa a dar la más fundamental que es su poder absoluto que no reconoce superior en las cosas terrenales, y entonces se lanza ya a exponer en qué consisten sus nuevos recursos. Se trata de vender a perpetuidad hidalguías, o de perpetuar las ya concedidas, a quienes le socorran con determinada cantidad dándoles consideración de hidalgos de sangre y solar conocido como son los hidalgos de Castilla, aun para aquellos que estuviesen en litigio sobre ello o les hubieran fallado en contra. El otro recurso-que es el que nos interesa-consiste en otorgar plena jurisdicción e independencia, con título de villa, a las aldeas, sujetas a la jurisdicción de las ciudades, que le entregasen la cantidad que la Princesa considerase conveniente. A poco más de un año, en 16 de enero de 1556, fatigado de tantos trabajos y algo enfermo, decide el Emperador retirarse al Monasterio de Yuste y su hijo y sucesor Felipe II se apresura a confirmar a su hermana, en 11 de mayo del mismo año, los plenos poderes que le había otorgado su padre, entre los que menciona el nuevo recurso de convertir las aldeas en villas.

Publicada por todo el Reino la nueva posibilidad que se ofrecía a los pequeños grupos urbanos de mejorar su situación, los vecinos del lugar de Aldea del Palo sintieron deseos de alcanzar esta independencia que les capacitaría para regirse a sí mismos y les libraría de una serie de inconvenientes que les acarreaba su dependencia de la Justicia de Zamora. Tenian algún dinero para reunir entre todos aquella cantidad, «que bien visto fuere a la Serenísima Princesa», según reza en la carta de poder de Carlos I a su hija, por lo que en el otoño de 1558, después de recogida la cosecha, se reunieron en Concejo los Alcaldes y Regidores, escuderos, oficiales y hombres buenos del lugar y eligieron a Hernando de Medina para que en nombre de todos hiciese las gestiones oportunas. Dirigióse éste a los altos poderes exponiendo las circunstancias favorables en que se encontraba el lugar, así como los motivos que justificaban su petición. Aldea del Palo tenía sus términos conocidos y amojonados con todos sus colindantes, excepto con los de Argujillo «porque es pasto común». Desde el lugar 
a Zamora había «quatro leguas grandes», «de muy malo y áspero camino» donde en tiempo lluvioso y de avenidas se formaban muchos atolladeros y trampales. En la Aldea sólo tenían jurisdicción en las causas civiles hasta la cuantía de cien maravedís y ninguna en lo criminal, dependiendo para esto de la ciudad de Zamora. Por esta causa mucha gente no quería pedir justicia por no tener dinero para costearse el desplazamiento, que suponía además el abandono de la labranza de sus heredades, $y$, sobre todo, se veían desamparados los pobres y viudas, quedando por este motivo sin sanción ni castigo muchos delitos. También se quejaban de que a veces, con poca o ninguna información, o por delitos muy pequeños, eran llevados presos los vecinos del lugar a la ciudad de Zamora, reteniéndolos muchos días. Por si esto fuera poco, los de los lugares vecinos entraban en sus términos a cortar leña y apacentar sus ganados sin que pudieran hacer nada por evitarlo o castigarlo, ya que no tenían jurisdicción para ello (7).

La Princesa Gobernadora, atendiendo a tantas razones, firma la concesión en nombre de Felipe $\Pi$ y accede a la demanda por los buenos servicios que le han hecho los vecinos y moradores del lugar y «por que nos servisteis, ayudasteis y socorristeis para las necesidades contenidas en nuestras dichas cartas de poder... y para otras necesidades que despues acá se han ofrecido para la guarda y provision de las fronteras de estos Reynos y de Africa, y para la paga de las galeras y otras cosas muy importantes con un quento y ciento y setenta mil mrs.», cuya cantidad se comprometen a pagar por medio de su representante a fines de noviembre del mismo año de 1558. Por el privilegio, en que dice "vos hago villa», les exime enteramente de la jurisdicción de la ciudad de Zamora concediéndoles para sí mismos jurisdicción civil y criminal «alta y baja, mero y mixto imperio» en el lugar, sus términos y dezmería, dentro de los límites y mojones que tiene en ese momento. Les autoriza a tener horca y picota, cuchillo, cárcel y cepo como lo tienen las demás ciudades y villas. Pueden en adelante elegir anualmente los cargos del Concejo constituídos por los Alcaldes ordinarios, un Alcalde de Hermandad, un algua-

(7) Relación de Hernando de Medina, en el Apéndice documental. 
cil, regidores, un mayordomo, un procurador, fieles, guardas y otros oficiales, como es costumbre en las villas realengas, los cuales Alcaldes y alguacil llevarán vara de justicia cuando ejerzan. su autoridad. Reserva para la Corona el derecho a nombrar escribano y el recurso de apelación en las Audiencias. Quieren también borrar su antigua humilde condición de aldea implícita en el nombre y así les concede que se puedan «nombrar, intitular y escrebir»Villa de San Miguel de la Ribera. Previene a los vecinos para que si fuesen requeridos por la Justicia de Zamora no acudiesen a su plazo y encarga especialmente a las autoridades de esta ciudad que no les entorpezcan en el ejercicio de sus nuevos derechos ordenando que remitan a la nueva villa de San Miguel de la Ribera, «que antes se llamaba Aldea del Palo», todas las causas civiles y criminales que estuvieran pendientes así como las comenzadas desde ocho meses antes, dando otras normas complementarias para evitar rozamientos y susceptibilidades. Teme el resentimiento de los zamoranos y previene que «no vos traten mal» por razón de haberse eximido de su jurisdicción. Autoriza a los vecinos de la nueva villa para que sus vecinos puedan hacer ordenanzas municipales siempre que las presenten a la aprobación del Consejo, pero les encarga especialmente que no modifiquen en nada las que estuvieren vigentes respecto a sus colindantes en lo relativo al uso de pastos, prados, abrevaderos, rozas, cortas de leña y labranzas, para que «no se entienda que a ninguna de las partes les damos, ni quitamos en ella más ni menos derecho de aquel que en justicia le pertenece». En tanto se hacen las nuevas ordenanzas les autoriza a poner guardas por su cuenta y que las prendas que tomen se juzguen por la justicia de la nueva villa. Especifica que los de Zamora pueden pasar por su territorio con vara de justicia cuando van a prender a alguien a otro lugar y no sólo no deben entorpecerlo, sino ayudarles. Quedan sujetos al Corregidor o Juez de residencia de Zamora en cuanto a que éste puede efectuar visita de residencia una vez al año y sólo por un plazo máximo de ocho días, no pudiendo reclamar a los Alcaldes las causas que tuvieren empezadas y debiendo devolver a la villa para su finiquito las que quedaren sin concluir cuando se ausentaren. 
Termina diciendo: «ponemos perpetuo silencio para agora $\mathrm{y}$ para siempre jamás entre los de la dicha villa de San Miguel de la Rivera y la dicha ciudad de Zamora y sus aldeas» para que «no vos puedan pedir ni demandar en ningún tiempo cosa alguna».

Esta carta de merced fue pregonada ante escribano, de orden de la Princesa, por las plazas públicas de la villa de San Miguel de la Ribera y las otras villas y lugares a los que pudiera interesar. Está fechada en Valladolid, a 9 de octubre de 1558 (8).

Debieron arreglarse bien haciendo suyas las ordenanzas que les habían correspondido hasta entonces como aldea de la ciudad de Zamora, pues hasta pasados treinta y dos años de su promoción no sintieron necesidad de hacer unas nuevas. En la primavera de 1590 nos encontramos con que han redactado un cuerpo legal propio en quince artículos, que en 4 de marzo son aprobados por el Consejo (9).

Examinando su contenido vemos que siguiendo su costumbre prescribe en primer lugar la elección de los cargos de Concejo el

(8) Véase Apéndice documental.

(9) «Por quanto por parte de vos el Concejo, Justicia y Regimiento de la villa de San Miguel de la Rivera nos fue fecha relacion que vosotros hauiades fecho ciertas ordenanzas cerca de la guarda, y conservacion de los panes, montes, huertas, y otros terminos de las quales haciades presentacion, y eran muy utiles, necesarias y provechosas para esa dicha villa, y vecinos de ella, y nos suplicastes las mandassemos confirmar para que fuessen guardadas, cumplidas, y ejecuradas, o como la nuestra merced fuesse, lo qual visto por los del nuestro Consejo, y ciertas diligencias, e informacion que sobre ello por provisiom nuestra ante ellos imbiaron los Alcaldes hordinarios de essa dicha Villa, y parecer que en ello dieron, y las dichas ordenanzas que son del thenor siguiente... (texto de las Ordenanzas).

... Fué acordado que debiamos mandar esta nuestra carta para vos en la dicha razon y Nos tuvímoslo por bien, por la qual sin perjuicio de nuestra corona real y de otro tercero alguno por el tiempo que nuestra merced y voluntad fuere confirmamos y aprobamos las dichas ordenanzas que de suso van incorporadas para que lo en ellas contenido fuesse guardado, cumplido y executado, y mandamos al que es o fuere de aqui adelante Alcalde mayor o hordinarios de essa dicha villa para que las guarden, cumplan y ejecuten y hagan guardar, cumplir y ejecutar y pregonar publicamente por las plazas y mercados y otros lugares acostumbrados de la dicha villa por pregonero $y$ ante escribano público por manera que venga a noticia de todos y ninguno pueda pretender ignorancia, de lo qual mandamos dar y dimos esta nuestra carta sellada con nuestro sello y librada de los del nuestro Consejo. Dada en Madrid a los quatro dias del mes de marzo.de mil y quinientos y noventa años». 
día de San Martín de noviembre (día 11). Enumera: Alcaldes ordinarios, Alcaldes de Hermandad, regidores, mayordomo, procurador y guardas de los montes y términos (10). En el mismo dia deberían elegir personas que demarcasen las tierras y viñas lindantes con caminos, cañadas y ejidos del Concejo, poniendo sus marcos o mojones de piedra, restituyendo los que se hubieran quebrado y poniendo multas a quienes los rompieren o mudaren para meterse a labrar en terrenos comunales (11).

En los restantes dedica un buen espacio a la protección de la agricultura, base económica de toda esta tierra de «pan» y «vino», imponiendo a los contraventores multas a repartir por terceras partes entre el guarda o denunciante, el dueño del cultivo y el juez que lo sentenciase.

Destácase en primer lugar el cultivo de cereales-trigo, cebada, centeno y avena - en forma semejante a como lo hacen otras villas circundantes. Los daños se gradúan por el tamaño y naturaleza del animal que entrare en ellos, de lo que dependía la cuantía del perjuicio, y también se tiene en cuenta la época del año en que se cometía la infracción, como condicionante del mayor o menor desarrollo de la cosecha, o su inexistencia. Así vemos cómo el ganado podía entrar en terrenos de este cultivo desde después de recogida la cosecha hasta el momento de la siembra. Desde la siembra hasta fin de febrero se penaba al ganado mayor con veinte maravedís por cabeza, quince para los asnos, diez los puercos y cabras y cinco las ovejas. A partir de primero de mar-

(10) Primeramente ordenamos que por el dia de San Martín de Noviembre de cada un año perpetuamente para siempre jamas se junte el Concejo, como tiene de uso, y de costumbre, é se nombren Alcaldes hordinarios, é Alcaldes de la hermandad, Regidores y Mayordomo é Procurador de Concejo, é guardas de los montes, y terminos, los quales en sus oficios guarden las leyes.

(11) Otrasi: ordenamos que todos los años por el dia de San Martín de cada un año cuando se eligieren los alcaldes e oficiales del Concejo, se nombre dos personas para que demarquen las tierras e vinas que lindaren con caminos, cañadas y exidos del Concejo y les ponga sus marcos de piedra y a las personas que hallaren metidos en cosa de Concejo o roto algun marco, demas de restituir lo que huviere tomado, le lleven ducientos maravedis aplicados por tercias partes, demarcadores, justicia y Concejo, y que la visita que sobre esto hiciere la justicia la haga con los demarcadores que salieren y con los que al presente fueren para que los pasados den mejor razon del sitio de los tales marcos. 
zo el dueño de los animales debería pagar, además de la multa consabida, el daño doblado al dueño del cultivo, según fuese tasado este daño por dos personas nombradas por la justicia, pudiendo sólo salvarse el acusado si tenía dos testigos a su favor. Llegado el verano y recogida la cosecha no se toleraba que anduviese suelto ganado alguno mientras el grano estaba en las eras, desde la puesta del sol hasta la hora de trillar, incurriendo en la multa de un real, si era todavía de día, y uno, si era por la noche, por cada cabeza de ganado que encontraren. Aun los patos, por su voracidad, eran penados con dos maravedís. Bastaba que fuera presentada la denuncia por el dueño de la cosecha con tres de sus criados o criadas como testigos (12).

Las mismas penas y disposiciones que ordenan la protección. de los cereales se aplican para proteger el cultivo de melonares, garbanzales y otros frutos tardíos, hasta tanto que llegase el momento de su recolección (13).

(12) Yttem; Por que haya buena guarda en los panes sembrados, ordenamos que todo ganado mayor, que son bueyes, bacas, mulas, rocines, yeguas, machos, que entraren en tierras de trigo, cevada, centeno y abena, que este sembrado, que se entienda desde que el pan se siembra hasta fin de hebrero de cada un año pague cada caveza del dicho ganado mayor veinte mrs., y las bestias asnales quince maravedís y los puercos diez maravedís y las cabras y cabrones por cada caveza diez maravedís, é las ovejas é carneros cinco maravedís por cada caveza hasta cinquenta cavezas é de ay arriba ansi en ganado ovejuno como el cabruno paguen seiscientos maravedís. Las quales dichas penas se lleven de dia y de noche doblado, y se repartan tercera parte para la guarda é denunciador é otra tercera parte para el dueño del tal pan, é otra tercera parte para el Juez que lo sentenciare. $\mathrm{Y}$ desde primero de hebrero en adelante hasta que el pan sea cogido y levantado en acinas de la tierra, los dichos ganados paguen la dicha pena repartida segun dicho es, é mas el daño que se aplica para el dueño del tal pan tasado por dos personas nombradas por.la Justicia, é sea bastante probanza el dicho y declaracion de la guarda o el dueño del tal pan con un testigo, excepto si probare al contrario con dos testigos fidedignos.

Otro si: Ordenamos que en el tiempo del verano, desde que se echa el par en las heras hasta que se levante, ningún genero de ganado ande suelto desde que se pone el sol hasta otro dia siguiente que sea hora de trillar so pena que qualesquier bacas y bueyes y bestias asnales, mulares y cavallares y lechones que se cogieren sueltas en las dichas heras pague cada caveza medio real de dia y de noche doblado y los patos dos maravedís cada uno; las quales dichas penas sean todas para el dueño del pan donde fuere tomado y sea bastante probanza el dicho del dueño y de sus criados y criadas como intervengan tres personas en la abriguación.

(13) Yttem. En lo que toca a la guarda de los melonares é garvanzales y las demas serondajas es cosa muy necesaria que esten guardadas todo el año hasta que se levanten de la tierra, ordenamos que los dichos 
Las viñas, por ser de cultivo constante, estaban vedadas todo el año, penando a los ganados mayores que entrasen en ellas con multa de treinta maravedís, es decir, diez más que si se tratase de sembrados de cereales, dado el tiempo mayor que se necesita para reponerlas. El resto de los animales incurrían en la misma penalidad que para los sembrados y sólo las ovejas pagan cuatro maravedís, o sea, uno menos, considerando sin duda que se limitaban en su mayoría a comer la hierba sin estropear los sarmientos. A partir del mes de mayo, en que las vides comienzan a echar brotes, tenían que pagar además al dueño de las vides el daño doblado (14).

En cuanto a las huertas, por estar muy cerca de la villa, se manda cercarlas de modo que no puedan entrar en ella animales «apeados» o trabados, so pena de no tener derecho alguno a reclamar por los daños sufridos. Las penas aplicadas eran las mismas que veremos para los sotos, más el daño tasado por dos personas nombradas por el Justicia, pudiendo salvarse el dueño del animal causante del perjuicio con dos testigos (15).

ganados mayores é menores que entraren en las dichas tierras donde estuvieren sembradas las dichas sarandajas paguen la dicha pena de dia y de noche segun de suso se contiene en el capítulo antes deste, e mas el daño para el dueño de la dicha serondaja y en la provanza y abriguacion se haga segun dicho es en el dicho capítulo.

La palabra serondaja, derivada de serondo o fruto tardío, significa to mismo y con este sentido se usaba en Salamanca en el siglo xvi, según el «Diccionario crítico etimológico de la lengua castellana», de J. Corominas.

(14) Yttem. Ordenamos que ningunas personas puedan meter sus ganados mayores ni menores en las viñas en ningun tiempo del año so pena que los dichos ganados mayores que entrassen en las dichas vifias paguen por cada caveza treinya maravedis de dia y las bestias asnales quince mrs. y lcs puercos y cabras diez mrs. cada caveza, y el ganado ovejuno quatro mrs. cada caveza hasta cinquenta y dende arrina anssi el cabruno como el ovejuno seiscientos mrs.; las quales dichas penas sean de dia y de noche doblado; y las dichas penas sean para la guarda tercera parte é otra tercera para el dueño de las tales viñas, é otra tercera parte para la Justicia que lo efectuare; é desde principio de Mayo que es quando las viñas comienzan a echar hasta fin de Octubre y en este tiempo los dichos ganados estando en las viñas hacen mucho daño, ordenamos que se pague la dicha pena repartida segun dicho es é mas el daño aplicado para el dueño de la viña donde se hiciere.

(15) Yttem. Ordenamos que para que las huertas sean guardadas que ningun genero de ganado pueda entrar en las huertas so la pena que está puesta a los que entraren en los sotos y mas paque el daño tasado por dos personas nombradas por la Justicia segun dicho es con tanto que las dichas huertas esten cercadas de suerte que el ganado apeado no pueda entrar en 
También las riquezas naturales reciben la debida protección, imponiendo fuertes sanciones a los que metiesen ganado en sotos y alamedas por ser mucha la necesidad que tienen de madera para los edificios y otras cosas y ser conveniente que los árboles, que están formándose, «se aumenten y crezcan», calculando que en seis años se podrá lograr mandan observar esta prohibición durante este plazo de tiempo. Como siempre, se estima en más el daño que pueda hacer el ganado vacuno al que se impone la misma pena que al ganado mayor que anduviese suelto por las eras en tiempo de trilla (30 maravedís). Baja para las yeguas, rocines y machos a veinte maravedís; los asnos y cabras pagan igual que en los sembrados (15 y 10 maravedís, respectivamente), y las ovejas como en las viñas (cuatro maravedís) (16).

Se regula el aprovechamiento de pastos en los prados llamados «sanjuaniegos» y el boyal de la Vega. Estos prados comunales estaban reservados al ganado mayor que podía disfrutar de ellos desde San Juan de junio (día 24) hasta primero de febrero, en que se vedan bajo multa de 10 maravedís de día y 20 de noche. En cuanto al prado boyal de la Vega, como se cortaba la hierba varias veces al año, no tenía tiempo fijo de coto, pero si entraba ganado mayor en tiempo acotado se incurría en la pena de un real de día y dos de noche. En lo que respecta al ganado menor no podía meterse a pastar en ninguna época del año bajo pena de dos maravedís de día y doble de noche (17).

ellas, é no estando cercadas no puedan prendar dellas, atento que las huertas estan muy cercanas de la villa é algunas dentro della por donde continuamente pasa el ganado. Para abriguacion del dicho daño sea creido la guarda por su juramento ecepto si se probare con dos testigos fidedignos lo contrario.

(16) Yttem. Por que hay mucha necesidad de madera para los edificios de las casas e otras cosas, é por que los sotos é alamaies en que se crian se aumenten é crezcan ordenamos que todos los ganados bacunos que entraren en los dichos sotos pague cada caveza treinta mrs. y las yeguas, rocines, machos y mulas cada caveza veinte mrs., y las bestias asnales quince mrs. y las cabras diez mrs.; los lechones y ovejas quatro mrs. por caveza hasta cinquenta y dende arriba seiscientos mrs.; y estas dichas penas sean de dia y de noche doblado, las cuales dichas penas apliquen al dueño de los sotos, Juez y denunciador por terceras partes, y esta ordenanza se guarde por tiempo de seis años.

(17) Yttem. Ordenamos que los prados que se llaman sanjuaniegos se guarden como es vso y costumbre desde primero de hebrero hasta San Juan de Junio luego siguiente de cada un ano; e todas las bestias mulares y ca- 
Considerando los daños que pueden hacer, en todo tiempo y en todo género de cultivos o riquezas naturales, las cabras, prohiben «para siempre jamás» que pueda haber en cada rebaño de cincuenta ovejas o más, número mayor a seis cabras cuando pastan por el monte de la villa, dado que es «novalío y bajo» y está en su mayor parte plantado de viñas (18).

Por evitar que los ganados se metan solos en los terrenos acotados próximos a la villa se manda cercar todas las viñas, tierras, cortinas (19), sotos y otros terrenos que lindan con las: casas de la villa, sin cuyo requisito los dueños no podrán denunciar los daños; a su vez dispone que los dueños del ganado echen las reses apeadas o trabadas para que los animales no puedan desplazarse con libertad, por donde vemos generaliza lo que ya se dijo para los cultivos de huerta (20).

vallares e asnales, bacas, bueyes que entraren en los dichos prados en todo el dicho tiempo paguen diez maravedis de dia y veinte de noche por cada. caveza; y llegado el dia de San Juan de Junio los dichos prados sean abiertos para los dichos ganados para que puedan pacer libremente en ellos hasta fin de henero luego siguiente; pero las cabras e cabrones, ovejas $y$ puercos ordenamos que en ningun tiempo del ano puedan entrar en los: dichos prados sanjuaniegos, ni en el prado boyal que llaman de la Vega so: pena que pague de pena por cada caveza dos maravedis de dia y de noche doblado hasta cinquenta cabezas y de ay arriba paguen dos reales de día y quatro de noche. Las quales dichas penas sean para el dueño de los dichos prados, juez y denunciador por tercias partes; y para llevar las. dichas penas sea creido la guarda de su juramento.

Yttem. Ordenamos que atento que el prado boyal de la Vega se cota muchas veces por ser prado boyal y de guadaña para los bueyes e mulas de labranza, ordenamos que el tiempo que estuviere coto por mandado del Concejo ningun ganado mayor pueda entrar a pacer en él so pena que por cada cabeza de bueyes, o baca o yegua, rocin, mula o macho paque un real de dia y dos de noche y las bestias asnales diez maravedis de dia y de noche doblado, y el ganado menor sea defendido todo el año so las dichas penas contenidas en el capitulo antes deste; las cuales dichas penas sean para el Concejo de la villa y juez y denunciador por tercias partes.

(18) Otrosi: por cuanto el monte de esta villa es novalío y bajo y el término de esta villa es corto y la mayor parte del plantado de vifas, que es todo el trato que tiene para pagar las alcabalas a su magestad, ordenamos que ahora y para siempre jamas ningun vecino pueda traher con su piara mas de seis cabras, y la piara se entienda de cinquenta cavezas arriba y que aunque la piara exceda de las dichas cinquenta cavezas no pueda exceder de las dichas seis cabras so pena de quatro reales cada vez que le fuere hallada alguna mas repartida por mitad para la guarda y Concejo.-Juan del Castillo.

(19) Llamaban cortinas a las huertas, cercados y corrales próximos a las casas. Todavía se conserva en uso en tierras de Zamora.

(20) Yttem. Ordenamos que los sotos que lindan con ejidos del Concejo 
También cuidaron los redactores de las ordenanzas de que no hubiera por causa de ellas motivo de rencillas entre los vecinos. Como se dijo al principio, el denunciante de una infracción tenía derecho a percibir la tercera parte del importe de la multa impuesta y temiendo rencores o falsas acusaciones prohibe que puedan denunciarse unos a otros; solamente lo pueden hacer los guardas de los panes y las viñas o el dueño de la heredad perjudicada, ya que de lo contrario la denuncia «podría ser con malicia e por llevar las dichas penas» (21).

Vela por la salud pública al prohibir que el ganado mayor y menor pueda sestear o dormir en el terreno comunal donde se encuentra el manantial que surte de agua a la villa "para que el agua de ella sea limpia y sana» (22).

Suponemos que disfrutaron de su autonomía en paz con sus

los tengan sus dueños cercados de manera que una res apeada é travada no pueda entrar en ellos, so pena que los dueños de los dichos sotos no puedan prendar ni llevar las dichas penas aunque hallen los dichos ganados dentro por que los dichos ganados de fuerza han de pacer de ordinario en los ejidos é non estando cercados los dichos sotos fácilmente se podran entrar en ellos, pero en los sotos y alamayes que estan fuera de los exidos aunque no esten cercados se guarden y no entren en ellos los dichos ganados so las dichas penas de suso; y esta ordenanza se guarde de por tiempo de seis años.

Yttem. Ordenamos que todas las tierras é viñas, herromiales, é cortinas que estan dentro de la villa é confinan con ella é con los exidos de Concejo, esten cercados de suerte que no pueda entrar una res apeada, é no estando cercadas como dicho es no puedan los dueños de ellas prendar ni llevar penas, y estando cercadas como dicho es pueda llevar la pena y penas y daños como se contiene en los capítulos destas dichas ordenanzas. (Véase en la nota 15 la misma disposición en cuanto a las huertas).

(21) Yttem. Ordenamos que ninguna persona pueda ser denunciada de las cosas contenidas en estas ordenanzas, ni llevar las penas della si no fuere la guarda de los panes e viñas o el dueño de la tal heredad, y esto se hace por que haya claridad e verdad en las denunciaciones e ninguna persona fuera de las sobredichas podría ser que con malicia e por llevar las dichas penas.

(22) Yttem. Ordenamos que por que la fuente de agua donde beben todos los vezinos de esta villa está en un exido de Concejo y es manantial y para que la agua de ella sea sana y limpia, ordenamos que ningún ganado ovejuno ni cabruno pueda asestar ni dormir en el dicho exido donde está la dicha fuente, atento que hace notable daño a la dicha fuente y agua $e$ manantiales de ella so pena que si sesteare o durmiere en el dicho egido el dicho ganado pague cinco maravedís por cada caveza hasta cinquenta y de ay arriba seiscientos maravedís aplicados por terceras partes la guarda, el Concejo, la justicia que lo sentenciare, y sea la guarda creida por su juramento. 
convecinos, como fue el deseo de la Princesa. Parece ser que en 1634 tuvieron necesldad de presentar el privilegio real ante el Corregidor de Zamora, que lo era a la sazón don Tomás de Tovar y Guevara, y del acto de acatamiento por el mismo dio fe el escribano real de la ciudad, Montesinos Chaves (23).

\section{A P E N D I E D O CUM E N T L}

Compra de la villa de San Miguel de la Rivera, año 1558.

Don Feliphe por la gracia de Dios Rey de Castilla, de León, de Aragón, etc.

Por quanto el Emperador y Reyna doña Juana, que sean en gloria, mis señores dieron una su carta de poder firmada de su mano y sellada con su sello para que la Serenísima Princesa de Portugal mi muy cara e amada hermana, Gobernadora de estos Reynos en ausencia de su Magestad e mía, pudiese exemir y apartar qualesquier lugares de la jurisdicion de la ciudades é villas a quien fuessen sujetos, y hacerlos villas de por sí como más largo en el dicho poder se contiene, é después el dicho Emperador mi señor por causa de sus indisposiciones y enfermedades renunció en mí esos Reynos y yo dí otra carta de poder firmada de mi mano y sellada con mi sello para la dicha Sereníssima Princesa, su thenor de los quales poderes es este que se sigue.

Don Carlos por la Divina Clemencia Emperador semper augusto Rey de Alemania, doña Juana su madre y él mismo don Carlos por la Gracia de Dios Reys de Castilla, de León, de Aragón, etc.

A los Infantes, Perlados, Duques, Marqueses, Condes, Ricos homes, Adelantados, Priores, Comendadores e Subcomendadores, Alcaides de los castillos e casas fuertes é llanas, é al nuestro Justicia mayor, é a los del nuestro Consejo, é Contadores mayores de Hacienda, é de cuentas, é otros nuestros oficiales, é Oidores de las nuestras Audiencias, Alcaldes, Alguaciles de la nuestra

(23) En la ciudad de Zamora a diez y ocho dias del mes de Henero de mil y seiscientos y treinta y quatro años de pedimento de la parte del Concejo de San Miguel de la Rivera yo el escrivano notifiqué y requerí con el real previlegio de atras al señor Don Thomas de Tovar y Guevara, cavallero de la Orden de Santiago, Corregidor desta dicha ciudad en su persona, el qual le obedeció con el acatamiento debido, y le besó y puso en su cabeza y dijo está pronto a cumplir lo contenido en el dicho real privilegio segun y en la forma que los demás corregidores desta ciudad sus antecesores lo han cumplido y guardado y en la forma que se ha usado del dicho privilegio. $\mathbf{Y}$ esto dí por su respuesta, siendo testigos Antonio de Ordás y Alonso Gómez, escrivanos del número de esta ciudad de Zamora y vecinos della. Don Thomas de Tobar y Guevara. Ante mi Montesinos Chaves escrivano del Rey nuestro señor y apostólico del número de esta ciudad de Zamora presente fú y en fee de ello lo signé. En testimonio de verdad Bernardo Montesinos Chaves. 
Casa, é Corte, é Chancillerías, é a los nuestros Capitanes de gente de armas, é a sus lugaresthenientes, é a todos los Concejos, Justicias, é homes buenos de todas las ciudades, villas e lugares de los nuestros Reynos é señoríos de Castilla, de León, é de Navarra, é de Granada é de las Yslas de Canaria, é de las Yndias, islas é tierra firme del mar oceano descubiertas é por descubrir, é a otras qualesquier de qualquier estado, condición, preheminencia, o dignidad que sean, a quien toca é atañe, é pueda tocar, é atañer en qualquier manera lo en esta nuestra carta conthenido é a cada uno en qualquier de vos, salud y gracia. Bien sabeis y a todos es notorio por lo que antes de agora havemos escrito a essos Reynos la causa de la salida de mi el Rey, y de vos esta ultima vez, en lo que despues ha sucedido, y el fin que con ayuda y favor de Nuestro Señor tuvo la guerra pasada de la germania, é quanto havemos deseado é procurado siempre la conservación de la paz por el bien público de la Christiandad y especialmente en esta coyuntura por [que] se continuase y acabasse el Sacro Concilio por lo mucho que importa para las cosas de nuestra Santa Fee Catholica, de la qual en algunas partes de la Christiandad estan muchos apartados, señaladamente en Alemania, é haviendo hecho sobre esto todas las justificaciones necesarias, no se ha conseguido el effecto que deseabamos, antes el Rey de Francia por impedirlo, siguiendo lo que acostumbra é sin tener ningun justo fundamento vino a romper la guerra por los términos que lo hizo, y no contento con esto trató é hizo liga contra Nos anssi con el Turco cuya armada ha solicitado y hecho salir, juntandose demas de esto con los navíos que hay en Argel, como con algunos Príncipes de la Germania desviados de la fee en daño universal de la Christiandad y Religion, y los unos y los otros han hecho e juntado poderoso ejercito y armadas para empecer y ocupar nuestros Estados patrimoniales de Flandes y forzarnos a desamparar el Ymperio, é levantar lo de Ytalia con título de lo de Sena, en lo qual se quería apoderar y alterar lo de Nápoles y ocupar lo que resta del Piamonte y el Estado de Milán, é para invadir é hacer males y daños en las costas y lugares marítimos de nuestros Reynos de Nápoles, Secilia y España y otros nuestros señoríos; por lo qual siendo como somos constreñidos a tratar del remedio, e obviar estos males y daños, é inconvenientes que se muestran a resistir a los enemigos por conservacion de la Religion Christiana y de nuestros Reynos y Estados, é autoridad y reputacion imperial en que si oviesse falta no podrian dejar de rescibir notable daño por los designos que sobre ello hace el dicho Rey de Francia y sus aliados y confederados, tenemos formados egercitos en Ytalia y en estas partes donde se halla presente la persona de mi el Rey para todo lo qual es necesario hacer muchos y grandes gastos de dineros, é por no bastar para ello nuestras rentas reales, ni los socorros, ayudas y servicios ordinarios y extraordinarios que los nuestros Reynos y otros Estados en todas partes nos han fecho 
y harán, ni lo que ha venido e verná de las Yndias, ni lo que se havrá del subsidio y bulas de Cruzada que nuestro muy Santo Padre nos tiene concedidas, ni de otras cosas extraordinarias, ni lo que se ha havido de las rentas y bienes y otras cosas que havemos vendido de nuestras Coronas y Patrimonios Reales de los dichos nuestros Reynos y Estados y Señoríos, havemos acordado de dar privilegios de hidalguías a algunas personas de los dichos nuestros Reynos de la Corona de Castilla que nos socorriesen é ayudaren para estas necesidades, é de dar jurediciones por sí y sobre sí, y hacer villas a los lugares de los dichos nuestros Reynos y Señoríos y de mandar que se use de todos arbitrios y cosas necesarias para aver dineros de todas las partes y dar poder especial para ello a la Serenísima Princesa de Portugal nuestra muy cara é muy amada hija é nuestra (1) Gobernadora en los dichos nuestros Reynos y Señoríos de la Corona de Castilla. Por ende por la presente de nuestro propio motu y cierta ciencia y poderío real absoluto de que en esta parte queremos usar y usamos como Reyes y Señores naturales no reconoscientes superior en lo temporal, damos todo nuestro poder cumplido, libre, llenero, bastante con libre y general administracion, segun que Nos lo havemos e tenemos y de hecho é de derecho mas puede valer y debe valer, a la dicha Serenísima Princesa de Portugal para que a todas las personas que ella quisiere y bien visto le fuere, que socorrieren é ayudaren para los dichos gastos y necesidades les pueda dar privilegios de hijosdalgo, é que las personas a quien los diere y sus hijos y descendientes gocen de todas las preheminencias y esenciones é inmunidades, franquezas, libertades y noblezas de hijosdalgo de Castilla, que son de sangre y solar conocido, devengar quinientos sueldos segun y como gozan los dichos hijosdalgo de España, é anssi mismo pueda prorrogar e confirmar qualesquier privilegios de cavallería, hidalguía, esencion y nobleza y amplearlos aunque se acaben en ellos o en qualquier de sus descendientes para que adelante dure para siempre jamas, a que si por caso alguna persona tuviere pleyto sobre su hidalguía $\mathrm{y}$, sin embargo de la lites pendencia, pueda hacer hidalgo, aunque contra él esten dadas qualesquier sentencias y cartas executorias dellas aunque sean pasadas en cosa juzgada, e que anssí mismo si le fuere pedido que estienda e confirme algun previlegio de nobleza, hidalguía, cavallería dado por nos o por los Reyes nuestros predecesores, aunque sea dado fuera de essos Reynos, lo pueda estender e emplear en ellos para que por virtud de los previlegios que les pidieren, usen de las preheminencias y esenciones de los tales previlegios contenidas en essos Reynos de España y de las demas que competen y competer deban a los hijosdalgo de España, de manera que la dicha Sereníssima Princesa lo concediere e ordenare. E otro si, para ennoblecer algunos lugares que son sujetos

(1) El texto pone erróneamente «nieta». 
a las ciudades y villas de los nuestros Reynos, si se quieren nombrar villas y exemirse e apartarse de las jurisdiciones donde son sujetos y obligados a ir a justicia, para que en los tales lugares se exercite nuestra juredicion alta, baja, mero, mixto imperio y se les cumpla nuestra justicia y se use en ellas de todas las otras cosas que se usan en las dichas ciudades y villas que tienen en sí el dicho exercicio de juridicion, socorriendo para estas necesidades con la contia que bien visto fuere a la dicha Sereníssima Princesa, les pueda apartar y eximir de las dichas ciudades y villas a quien son sujetos, $\mathrm{y}$ hacerlos villas $\mathrm{y}$ darlos juridicion por sí y que puedan usar de todos los otros arbitrios y cosas, formas y maneras que le pareciere para aver dinero para las muchas necesidades, e que pueda hacer e celebrar sobre lo suso dicho, e qualquier cosa e parte dello y lo a ello anejo e concerniente en qualquier manera todas y qualesquier contrataciones, contratos y obligaciones y escripturas que sean necesarias y dar qualesquier carta de previlegios para entera firmeza e seguridad de todo lo que dicho es con todas las cláusulas, vínculos y firmezas que sean necesarias, e para que pueda mandar librar é despachar qualesquier nuestras cartas de previlegios y otras provisiones que para validacion e firmeza de ello sean necesarias; las quales y todo lo que la dicha Princesa en nuestro nombre en la dicha razon hiciere queremos que valga é sea firme e valedero como si nos mismos lo hiciessemos y fuese firmado de nuestra mano; é decimos é otorgamos é prometemos que lo havremos todo por firme, estable e valedero para agora e para siempre jamas, é que no lo rebocaremos ni iremos, ni mandaremos ir contra ello, ni contra cosa alguna, ni parte de ello en tiempo alguno, ni por alguna manera; lo qual todo queremos y es nuestra voluntad que se haga, cumpla e guarde no embargante las prematicas y esenciones de los dichos nuestros Reynos que disponen que no se den cartas de hidalguías a personas algunas y que si se dieren no se entienda a la exencion, sino quanto a las monedas, señaladamente la premática del Rey don Juan el Segundo, fecha en Valladolid a quince dias del mes de Diciembre del año pasado de mil y quatrocientos y quarenta y siete años, en otrosí no embargante qualesquier leyes, fueros é derechos, usos y costumbres, premáticas sanciones de los dichos nuestros Reynos fechas en Cortes o fuera dellas, con lo qual é qualesquier otras cosas que haya en contrario a lo contenido en esta nuestra carta y a lo que por virtud della y conforme a ella se hiciere pueda obstar en qualquier manera, con las quales del dicho nuestro propio motu é cierta ciencia é poderío real absoluto de que en esta parte queremos usar e usamos, dispensamos y lo abrogamos é derogamos, casamos é anulamos, é damos por ningunos, é de ningun valor y effecto en quanto a esto toca quedando en su fuerza é vigor para en todo lo demás adelante, é por esta nuestra carta mandamos a los dichos nuestros Contadores mayores, é al nuestro Mayordomo, é Chanciller mayores, é 
confirmadores, é a los otros oficiales que estan a la tabla de los nuestros sellos, que den, libren é despachen é sellen para el dicho effecto todos los previlegios y confirmaciones, cartas é provisiones que fueren necesarias conforme a lo que la dicha Princesa mandare, bien anssi como si nos lo mandassemos, sin poner en ello embargo, ni contrario alguno, no embargante qualesquier leyes y cosas que haya en contrario; con lo qual todo Nos dispensamos é relebamos a ellos de qualquier cargo o culpa que por ello les pueda ser imputado, de lo qual mandamos dar la presente firmada de mí el Rey y sellada con nuestro sello, dada en la villa de Betuna a primero dia del mes de Septiembre de mil é quinientos y cinquenta y quatro años. Yo el Rey. Yo Francisco de Heraso Secretario de su Cesaria y Catholicas Magestades la fice escrebir por su mandado. El Licenciado Menchaca. El Licenciado Vinuesa de Munatones. Registrada: Martin de Vergara por Chanciller.

Don Phelipe por la gracia de Dios Rey de Castilla, de León, de Aragón, de Inglaterra é Francia, etc.

A los Infantes, Perlados, Duques, Marqueses, Condes, Ricos homes, Adelantados, Priores, Comendadores y Subcomendadores, Alcaides de los castillos é casa fuertes é llanas, y al mi Justicia mayor, é a los del mi Consejo é Contadores mayores de Hacienda é de quentas é otros mis oficiales é Oidores de las mis Audiencias, Alcaldes, Alguaciles de la mi Casa é Corte é Chancillerías, é a los mis Capitanes generales y a los Capitanes de gente de armas é a sus lugares tenientes, é a todos los Concejos, Justicias, Regidores, Cavalleros, Escuderos, Oficiales é hombres buenos de todas las ciudades, villas y lugares de los mis Reynos y Señoríos de Castilla y de León, de Navarra y de Granada, de las Yslas de Canaria, de las Yndias, Yslas y Tierra Firme del mar oceano descubiertas y por descubrir, y a otras qualesquier personas de qualquier estado, condicion, preheminencia o dignidad que sean a quien lo conthenido en esta mi carta toca y atañe y atañer puede en qualquier manera, é a cada uno é qualesquier de vos, salud y gracia. Bien sabeis como por el ausencia que para cosas muy grandes, é de ymportancia yo hice desos Reynos, el Emperador mi señor nombró é proveyó a la Sereníssima Princesa de Portugal, mi muy cara y muy amada hermana, por su Gobernadora, é Lugartheniente general en essos dichos Reynos, dandole para ello y para otras cosas sus poderes bastantes, conbiene a saber: uno para la dicha gobernacion; otro para la administracion de las tres Ordenes de Santiago, Calatrava y Alcántara; y otro para que pueda dismembrar de las dichas Ordenes y mesas maestrales y encomiendas de ellas y vender lo que se dismembrare por vertud de las bulas y breves que estan concedidas y aprobadas por los Sumos Pontífices y otros poderes para otras cosas, é anssi mismo una cédula para que los mis Contadores mayores de la Hacienda despachen las cartas de privilegio é otras cartas 
que la dicha Sereníssima Princesa les mandasse de los maravedís de juro que oviessen de hacer las Ordenes y Encomiendas en equivalencia de lo que dellas se dismembrasse y vendiesse; los quales dichos poderes y cédula se dieron en la villa de Bruselas a postrero de marzo e primero de Abril del año pasado de mil é quinientos é cinquenta y quatro; é después en la villa de Betuna a primero dia del mes de Septiembre del dicho año de quinientos e cinquenta y quatro, su Magestad dió otros poderes especiales a la dicha Sereníssima Princesa, uno para que pudiesse vender qualesquier rentas é maravedís de juro, pan y aceite, é otros derechos pertenecientes a la Corona é Patrimonio real, perpetuamente o alquitar, con que no fuessen alcabalas, é otro para que pudiesse vender alquitar vasallos, villas é lugares é fortalezas con las rentas, jurediciones, pechos é derechos é otras cosas a ellas pertenecientes; é otro para dismembrar y vender, en virtud de la bula que para ello nuestro muy Santo Padre Julio Tercio concedió a su Magestad, vasallos de los monasterios de las Ordenes de San Benito y San Bernardo y otras Ordenes, y otro para que pueda dar hidalguías y juridiciones segun que todo lo suso dicho y otras cosas en los dichos poderes y cada uno de ellos mas largamente se declara. Despues de la qual su Magestad, por sus muchas e continuas enfermedades y no hallarse con salud para poder tratar los negocios, ni asistir en ellos y ni mucho menos para visitar personalmente sus Reynos y Estados, y por otras suficientes causas é razones, tuvo por bien de renunciar, como renunció y traspasó en mi essos dichos Reynos e Señoríos como se contiene en la escritura que sobre ello su Magestad otorgó en la villa de Bruselas a diez y siete dias del mes de Henero deste presente año de mil é quinientos é cinquenta é seis años a que me refiero. $\mathrm{E}$ por que durante mi ausencia dessos Reynos es mi voluntad é conviene a mi servicio que la dicha Sereníssima Princesa sea Gobernadora y lugartheniente general en ellos, por la presente, de mi propio motu y cierta ciencia y poderío real absoluto de que en esta parte quiero usar é uso como Rey é Señor natural, no reconociente superior en lo temporal, doi y otorgo mi poder cumplido, libre, llenero y bastante, segun que le he y tengo, é de hecho é de derecho mas pueda e deba valer a la dicha Sereníssima Princesa para que por mí y en mi nombre y como yo mismo durante mi ausencia dessos dichos Reynos é Señoríos sea Gobernadora y lugartheniente general en ellos segun y de la misma forma e manera que lo ha sido hasta aquí, ansí en lo tocante a la dicha gobernacion como en la administracion de las dichas tres Ordenes é dismembraciones de las mesas maestrales y encomiendas y ventas de juros, pan, aceite, vasallos y todo lo demas contenido en los dichos poderes que de suso se hace mincion que el Emperador mi señor le dió, y en cada uno de ellos, los quales ratifico y apruebo en todo y por todo como en ellos se contiene y se los doi é otorgo de nuevo con las mismas facultades y pode- 
res y clausulas en los dichos poderes que de su Magestad tenía conthenidas, las quales todas de nuevo le concedo y quiero que haya como si aquí fuessen especialmente puestas y declaradas, y quiero y es mi voluntad que lo que por virtud y conforme a ello ha hecho é hiciere desde el dicho dia diez y seis de Henero deste dicho presente año que su Magestad me renunció y traspasó essos Reynos hasta oy, y lo que hiciere, concediere é despachare é capitulare desde oy en adelante, sea firme é valedero para agora é para siempre jamas, bien anssi ya tan cumplidamente como si fuesse hecho y provehido por mí y firmado de mi mano, y prometo que lo havré todo por firme, rato, grato, estable, valedero é que no lo revocaré, ni iré, ni mandaré ir contra ello, ni contra cosa alguna ni parte dello en tiempo alguno, ni por alguna manera no embargante qualesquier leyes e dehechos, usos é costumbres especiales é generales que en contrario haya, con las quales é con cada una dellas y con otras qualesquier cosas que a lo conthenido en esta mi carta pueda obstar en qualquier manera dispenso é lo abrogo é derogo, caso é anulo, é doi por ninguna é de ningun valor y effeto en quanto a esto toca quedando para todo lo demás en su fuerza é vigor que para todo lo que dicho es, é lo a ello anejo é concerniente le doi é otorgo el dicho mi poder cumplido con todas sus incidencias, mergencias (sic) y dependencias, anejidades y conexidades; y quiero que este poder tenga tanta fuerza como si fuera otorgado en Cortes generales é a pedimento de los Procuradores dessos Reynos, y por que en la dicha carta de poder que sus Magestades dieron a la Sereníssima Princesa para vender maravedís de juro perpetuo, o alquitar, dice que por virtud del no se puedan vender ningunos maravedís de las alcabalas alquitar, ni perpetuamente y algunos diz que dudan si por vertud del dicho poder se pueden vender maravedís de juro perpétuo o alquitar para que se situen en las alcabalas de las ciudades, villas é lugares de estos Reynos; por la presente declaro que la dicha limitación se entiende para que no se puedan vender las alcabalas de algunas villas é lugares destos Reynos enteramente como se solian vender perpétuos o alquitar para que las personas que las compraban las arrendassen é beneficiassen é cobrassen para sí conforme a la Ley del Quaderno, aunque las dichas alcabalas valiesen mucho mas del precio por que se vendían, y que no se entiende, ni estiende a los maravedís de juro perpetuo, o alquitar que qualesquier personas han comprado o compraren por virtud del dicho poder, o quisieren comprar de aquí adelante para que les sean situados en las alcabalas de qualesquier ciudades, villas é lugares dessos Reynos como hasta aquí se ha hecho. $\mathrm{E}$ otro si: por que después que sus Magestades dieron el dicho poder a la dicha Sereníssima Princesa, sus Magestades por otra su carta firmada della fecha en la villa de Valladolid a diez dias del mes de Abril del año pasado de quinientos y cinquenta e cinco, dieron licencia y facultad a qualesquier personas 
que tuvieren qualesquier maravedís de por vida por merced o comprados con facultad de su poder quitar, e a otras qualesquier personas que por ellos lo oviessen de gozar durante las vidas de las personas que los tenían é tienen para que los pudiessen hacer de juro alquitar dejando para sus Magestades los maravedís de por vida que tuviesen, o de que gozasen, contados a siete mil maravedís el millar, é dando sobre ellos otros siete mil maravedís en cada millar para ayuda a las necesidades que se han ofrecido é ofrescen, é que dellos se les diessen cartas de previlegio de sus Magestades, y que lo mismo pudiessen hacer qualesquier de las dichas personas que dejassen dos mil maravedís de por vida por cada millar de los de juro; por que crecello e bajallos en la forma suso dicha para lo que a sus Magestades tocaba era todo una misma cosa, segun mas largo en la dicha carta se contiene, é por vertud della e de una cédula de su Magestad firmada de la dicha Princesa se han crescido algunos de los dichos maravedís de por vida é otros se han bajado y dellos se les han dado cartas de previlegios de sus Magestades, é mas y se entiende que otras personas cresceran o bajaran los maravedís de por vida que tienen o de que gozan como se ha fecho hasta aquí; por ende por la presente ratefico e apruebo todo lo que por virtud de las dichas cartas y cédula que se han dado y de otras qualesquier que de aquí adelante se dieren durante mi ausencia, sea fecho é ficiere cerca de los suso dicho en todo como en las dichas cartas y cédula se contiene e contuviere y quiero que valga y tenga tanta fuerza e vigor como si fuere firmado del Emperador mi señor o de mí después que su Magestad me renunció essos Reynos y que las dichas personas que han crecido o bajado los dichos maravedís de por vida, y los que los crecieren o bajaren de aquí adelante y sus herederos y subcesores, o quien dellos tiene o tuviere título o causa, tengan los dichos maravedís de juro de que se les han dado o dieren privilegios con todas las facultades y seguridades é firmezas en las dichas carta é cédula conthenidas; de lo qual mandé dar y dí la presente firmada de mi nombre y sellada con mi sello en la villa de Bruselas a once dias del mes de Mayo de mil y quinientos e cinquenta y seis años. Yo el Rey. Yo Francisco de Heraso Secretario de su Magestad Real la fice escrivir su mandado. El Licenciado Menchaca. Registrada Martin de Bergara. Martin de Bergara por Chanciller.

$\mathrm{E}$ agora Hernando de Medina en nombre de vos el Concejo, alcaldes é regidores, escuderos, oficiales é homes buenos del lugar de Aldea del Palo que ha sido tierra é jurisdicion de la ciudad de Zamora nos fué fecha relacion que en el dicho lugar hay ciento y ochenta vezinos y tienen dezmería, términos y sitios amojonados $\mathrm{y}$ divididos y apartados por sus hitos y mojones, y de los lugares con quien confinan que es por la una parte con término de la villa de Fuentes Preadas y del Piñero y con término de la villa de Venialbo y con términos y montes de la ciudad de Toro 
y de la villa de Villamor, y con términos de la villa de Argujillo; todos los quales dichos términos tienen sus mojones divididos $\mathrm{y}$ conocidos y apartados entre el dicho lugar y las dichas villas excepto por la parte que confina con la dicha villa de Argujillo que no estan los términos divididos, amojonados y apartados por que es pasto común entre los vecinos desse dicho lugar y la dicha villa de Argujillo de campana a campana, excepto en las labranzas de cada lugar, que están divididas y apartadas; en los quales dichos términos y dezmería havrá de largo tres quartos de legua y de ancho media legua poco mas o menos, y que desde esse dicho lugar de Aldea del Palo a la dicha ciudad de Zamora hay quatro leguas grandes de muy malo y áspero camino donde en tiempo lluvioso y de avenidas hay muchos atolladeros y trampales y que los Jurados de esse dicho lugar tienen jurisdicion en las causas ceviles solamente hasta en quantía de cien maravedís y en las causas criminales no tienen jurisdición ninguna mas de prender y remitirlos presos a la Justicia de la dicha ciudad de Zamora, y que los vecinos de esse dicho lugar hacen muchas costas y gastos en ir a juicio a la dicha ciudad y algunas veces los pobres y viudas y otras personas dejan de pedir y seguir su justicia y de se defender de los que algo les piden y demandan por no poder ir a la dicha ciudad de Zamora a seguir sus pleitos y causas que les suceden y si van han de dejar de labrar en sus heredades y anssi pierden lo que les es devido y no se defienden de lo que les piden injustamente; y que por no tener en el dicho lugar jurisdicion en las causas ceviles mas de los dichos cien maravedís, y en las criminales ninguna jurisdicion muchas veces quedan los delitos que se cometen en él y en sus términos y dezmerías sin pugnicion ni castigo y las partes dagnificadas; y que otras veces por delitos muy pequeños, con poca o ninguna informacion, llevan presos a los vecinos de esse dicho lugar a la dicha ciudad, donde los tienen presos muchos dias y que demas desto, por estar sugetos los vecinos desse dicho lugar a la jurisdicion de la dicha ciudad de Zamora, reciben muchas fatigas, molestias y vexaciones de alguaciles, escrivanos, executores, y emplazadores y guardas y en otras diversas formas y maneras; y que los vecinos y moradores de otras villas y lugares comarcanos entran en los términos desse dicho lugar a cortar leña y a pastar con sus ganados y que por no tener en el dicho lugar jurisdicion no los osan, ni pueden prender ni defender que no los corten ni pas-

$n$ los dichos sus términos, y nos suplicastes y pedistes por merced proveyesemos como los dichos daños é inconvenientes cesassen y vos hiciessemos merced de vos eximir y apartar de la jurisdicion de la dicha ciudad de Zamora y vos diessemos jurisdicion civil y criminal, alta y baja, mero y mixto imperio en esse dicho lugar y en los dichos sus términos y sitio y dezmería y vos hiciessemos villa por vos y sobre vos en quanto toca a la dicha juridicion o como la mi merced fuesse. E nos acatando lo suso 
dicho é algunos buenos servicios que esse dicho lugar é vecinos é moradores del nos han hecho y esperamos que nos haran, y por que nos servistes, ayudastes y socorristes para las necesidades contenidas en las dichas nuestras cartas de poder suso incorporadas, y para otras necesidades que después acá se han ofrecido para la guarda y provision de las fronteras destos Reynos y de Africa, y paga de las galeras y otras cosas muy importantes con un quento y ciento y setenta mil maravedís los quales el dicho Hernando de Medina en vuestro nombre se obligó de nos los pagar para en fin del mes de Noviembre primero que viene deste presente año de mil é quinientos e cinquenta y ocho años, y por otras muy justas causas y consideraciones que a ello nos mueven de que somos informados y certificados, y por que a Nos como a Rey y señor natural pertenece propiamente eximir é apartar los unos lugares de la jurisdicion de los otros y unirlos a la jurisdicion de los otros cada y cuando que nos pareciere que conviene a nuestro servicio y al bien y provecho común de los dichos lugares o de alguno dellos, por la presente por vos hacer bien y merced de nuestro propio motu y ciencia cierta y poderío real absoluto de que en esta parte queremos usar é usamos como Rey y señor natural no reconociente superior en lo temporal, es mi merced y voluntad de vos eximir é apartar é por la presente vos eximo y aparto de la juridicion de la dicha ciudad de Zamora y de nuestro Corregidor y otros qualesquier jueces justicias della y vos hago villa para que en ella $\mathrm{y}$ en los dichos sus términos y sitio y dezmería como agora estan deslindados y amojonados y conocidos se use y egerza nuestra juridicion civil y creminal segun. y como se usa en la dicha ciudad de Zamora entre los vecinos y moradores estantes y habitantes della, y queremos que en essa. dicha villa haya horca y picota, cuchillo, carcel y cepo y todas las otras cosas e insinias de juridicion que las ciudades y villas por sí y sobre sí de estos nuestros Reynos que son libres y esemptas de otra juridicion tienen y usan; y por la forma y manera. que la ha tenido y usado la dicha ciudad y la Justicia della en essa dicha villa anssi en las causas criminales como en las civiles de qualquier calidad y cantidad que sean, y useis y goceis de la dicha juridicion de aquella misma forma que hasta aquí podía y debía usar y gozar la Justicia de la dicha ciudad de Zamora y el nuestro corregidor della, y para ejercer y usar la dicha jurisdicion podais eligir y nombrar en cada año dos alcaldes ordinarios y un alguacil y regidores y un mayordomo y procurador, fieles y guardas y otros oficiales que se suelen y acostumbran eligir y nombrar en las villas realengas destos nuestros Reynos que tienen jurisdicion por sí y sobre sí para que usen los dichos oficios en essa villa de Aldea el Palo y en los dichos sus términos, sitio y dezmería; a los quales dichos alcaldes y alguaciles damos poder y facultad para que en nuestro nombre puedan traher y traigan vara de la nuestra justicia y los dichos alcaldes. 
conozcan de todos los pleitos y causas civiles y criminales de qualquier calidad $\mathrm{y}$ cantidad que sean que en essa dicha villa de Aldea el Palo y en su sitio, términos y dezmería acaecieren y se comenzaren y movieren de aqui adelante y segun y como y de la manera que conocen y pueden conocer los otros alcaldes de las otras villas realengas de estos nuestros Reynos que tienen juridicion por sí y sobre sí segun que la Justicia de la dicha ciudad de Zamora lo egercía en essa dicha villa y en sus términos y dezmería en las dichas causas criminales y civiles, y desde agora para entonces damos poder cumplido a los dichos alcaldes y alguacil para usar y egercer los dichos oficios y para el conocimiento y determinacion y egecucion de los dichos pleitos y causas criminales y ceviles $\mathrm{y}$ anssí mismo damos el dicho poder a los otros oficiales suso declarados en los casos y cosas a ellos anejas y concernientes en essa dicha villa de Aldea el Palo y en los dichos sus términos y sitio y dezmería segun y como y con las facultades y de la manera que lo usan los otros oficiales de las otras villas realengas destos dichos nuestros Reynos como dicho es, quedando en nos y en nuestra Corona Real todo aquello que pertenece al supremo y soberano señorío, juridicion y apelacion para las nuestras Audiencias. $Y$ otrosi vos damos poder cumplido para que os podais nombrar, intitular y escrebir villa, é nombraros la villa de San Miguel de la Rivera. Como tal villa queremos y es nuestra voluntad que goceis y vos sean guardadas perpetuamente para siempre jamas todas las honras, gracias, mercedes, franquezas y libertades, esenciones, preeminencias, prerrogativas e inmunidades y todas las otras cosas y cada una dellas que se guardan y suelen y deben guardar a las otras villas realengas destos nuestros Reynos. Y mandamos al nuestro corregidor o juez de residencia de la villa de Zamora, o su alcalde ó lugar theniente en el dicho oficio anssi al que agora es como a los que son ó fueren de aqui adelante y a otras qualesquier justicias $\mathrm{y}$ al Concejo, justicia y regidores, cavalleros, escuderos, oficiales y homes buenos de la dicha ciudad de Zamora y sus aldeas, $y$ de otras qualesquier ciudades, villas é lugares que agora ni en tiempo alguno ni por alguna manera no se entrometan a os perturbar la dicha juridición que anssi vos concedemos y es nuestra merced y voluntad que tengais y que para ello vos degen y consientan tener la dicha horca y picota y otras insinias de juridicion que eligiéredes y pusiéredes sin vos poner en ello ni en cosa alguna ni en parte dello ningún impedimento ni contradición, y que remitan a los alcaldes dessa villa de San Miguel de la Rivera que antes se llamaba Aldea el Palo todas las causas anssi criminales como civiles que esten pendientes ante la Justicia de la dicha ciudad de Zamora que se han comenzado y movido de ocho meses a esta parte, y los procesos que tuvieren para que se acaben y se fenezcan en essa dicha villa por los dichos alcaldes della; y que no entren en essa dicha villa de San Miguel de la 
Rivera y su dezmería, ni en los dichos vuestros términos donde os damos la dicha juridicion a os visitar, ni prender, ni prendar, ni hacer ni hagan otra justicia alguna salvo por la forma y manera que de yuso se contiene so las penas en que caen los que entran en juridicion estraña, y mandamos que no vos citen, llamen, ni emplacen para pleitos ni causa alguna que de aquí adelante se muevan a ningun vezino de la dicha villa de San Miguel de la. Rivera y su término para la dicha ciudad de Zamora, y si os: citaren, llamaren o emplazaren que no seais obligados de ir ni vays (sic) a los dichos plazos ni llamamientos, ni seais havidos por contumaces, ni reveldes por no ir a ellos; y que por razon de haverse eximido essa dicha villa de San Miguel de la Rivera de la juridicion de la ciudad de Zamora no vos traten mal ni vos muevan pleitos algunos; y es nuestra voluntad que por esta dicha mi merced que vos hacemos no se entienda inovar cosa alguna en lo tocante a los pastos, prados y abrebaderos, rozas, cortas y labranzas y otros qualesquier aprovechamientos y otras cosas entre la dicha ciudad de Zamora y sus aldeas y las otras villas y lugares de su comarca y essa dicha villa de San Miguel de la Rivera; antes queremos y mandamos que las cosas sobredichas y cada una dellas queden, esten y sean de la forma y manera que han sido y estado en tiempo que essa dicha villa de San Miguel de la Rivera era aldea de la dicha ciudad de Zamora, y que quanto a esto no se haga novedad alguna, salvo que se use por la dicha ciudad de Zamora y por vos como hasta aquí se ha usado y que por virtud desta nuestra carta no se entienda que a ninguna de las partes les damos ni quitamos en ella mas ni menos derecho de aquel que de justicia les pertenece excepto en quanto toca a la dicha juridicion que ha de quedar en la dicha villa de San Miguel de la Rivera como dicho es y reservando para nos y para los reyes que después de nos fueren la provision de la escribanía. dessa dicha villa anssí de lo criminal como de lo civil y concejo para que la podamos proveher a quien nuestra merced y voluntad fuere; la qual dicha merced y esencion vos facemos con que el Concejo de la dicha ciudad de Zamora y el dessa dicha villa de San Miguel de la Rivera puedan hacer ordenanzas, cada Concejo en las cosas que las solía hacer, como les pareciere que convienen con que no se use dellas, ni se ejecuten sin que primeramente sean vistas en el nuestro Consejo y confirmadas por nos y que los vecinos y moradores de la dicha ciudad y los dessa dicha villa sean obligados a guardar las ordenanzas que cerca de lo susodicho estan fechas y las que adelante se hicieren en la forma susodicha, conviene a saber cada Concejo las que le incumbe, siendo como dicho es confirmado por nos y que las guardas que ha acostumbrado a poner la dicha ciudad de Zamora sean. puestas y se pongan en los términos dessa dicha villa por la. dicha ciudad, segun y de la manera que hasta aquí se han puesto $\mathrm{y}$ acostumbrado poner y que assi mismo essa dicha villa pueda 
poner guardas en los términos della donde os damos la dicha juridicion, aunque hasta aquí no las haya puesto, y que las prendas que por qualquier de las dichas guardas se tomaren dentro del término dessa dicha villa se juzguen por la Justicia della y no en la dicha ciudad de Zamora. Y otrosi: con tanto que si la Justicia de dicha ciudad de Zamora inbiare a prender alguna persona de alguno de los lugares de la juridicion de la dicha ciudad a facer alguna ejecucion o otros autos de Justicia, que el que fuere a lo suso dicho pueda pasar con una vara por essa dicha villa y sus términos y juridicion anssí a la ida como a la buelta con los presos y prendas y otras cosas que trujere y llevare sin que le sea puesto impedimento alguno; y que los vecinos dessa dicha villa sean obligados de les favorecer y ayudar para ello con que los tales alguaciles y egecutores no puedan usar ni usen de otra juridición ni otra cosa alguna en essa dicha villa y sus términos y dezmería. $\mathrm{Y}$ otrosí con tanto que la dicha villa quede en el Corregimiento de la dicha ciudad de Zamora para que si el nuestro Corregidor o Juez de residencia, o su lugartheniente que ordinariamente reside en el dicho oficio, quisiere ir a vesitar essa dicha villa de San Miguel de la Rivera y sus términos y dezmería y la Justicia y oficiales della, y estar y residir en ella, lo pueda hacer y haga una vez en cada año, con tanto que no pueda estar ni residir en essa dicha villa mas de ocho dias y que en el tiempo que de los dichos ocho dias residiere en ella, y no de otra manera, pueda conocer y conozca en primera instancia de todos los pleitos y causas criminales y ceviles que en ella subcedieren y se movieren segun y como agora lo hace en la dicha ciudad de $\mathrm{Za}$ mora; y que haya lugar en la dicha primera instancia prevencion entre él y los alcaldes ordinarios de essa dicha villa con tanto que no pueda advocar a sí los pleitos que estuvieren pendientes ante los dichos alcaldes y que use el dicho oficio de nuestro Corregidor en esa dicha villa con nuestro escrivano o escrivanos del número y alguacil della y que no pueda usar ni use de la dicha juridicion en essa dicha villa ni en sus términos con escrivano ni alguacil de la dicha ciudad de Zamora, ni de otra parte, y que quando saliere de essa dicha villa remita los procesos de qualesquier pleitos y causas creminales y ceviles que ante él se ovieren comenzado a los alcaldes ordinarios de essa dicha villa para que ellos los fenezcan, acaben y sentencien definitivamente. Y mandamos que en las apelaciones que se interpusieren de hasta en quantía de los seis mil maravedís anssi de los alcaldes ordinarios dessa dicha villa como del dicho nuestro Corregidor de Zamora, o su lugartheniente, quando conforme a lo susodicho en ella estuvieren, se guarden las leyes, capítulos de Cortes y ordenanzas de los Reynos que sobre ello disponen; sobre todo lo qual que dicho es encargamos al Serenísimo Príncipe don Carlos, mi muy caro y muy amado hijo, y mandamos a los Infantes, Duques, Marqueses, Condes, Perlados, Ricos homes y a los del nuestro Consejo y Oido- 
res de las nuestras Audiencias, Alcaldes y Alguaciles de la nuestra Casa y Corte y Chancillerías, y a los Priores, Comendadores y Subcomendadores, Alcaides de los castillos y casa fuertes y llanas, y a todos los Concejos, Gobernadores, Asistentes, Alcaldes, Alguaciles, Regidores, Jurados, Cavalleros, Escuderos, Oficiales y homes buenos de todas las ciudades villas y lugares de los nuestros Reynos y Señoríos, Ordenes, Abadias y Beetrías, y a cada una dellos (sic) anssí a los que agora son como a los que serán de aquí adelante, que vos guarden y cumplan y hagan guardar y cumplir esta dicha merced y esención que vos hacemos en todo y por todo como en esta nuestra carta de merced se contiene y que no consientan ni den lugar que contra el thenor y forma della persona o personas algunas hayan y pasen, ni consientan ir ni pasar en tiempo alguno ni por alguna manera; y si sobre lo que aquí va expresado y declarado os pusieren alguna demanda o dieren alguna peticion contra vos, que no los oigan enjuicio ni fuera del ca nos los inhibimos del conocimiento de lo suso dicho, salvo que lo remitan a nuestra Persona Real o a los del nuestro Consejo para que nos lo mandemos ver y proveer no embargante qualesquier pleitos que sobre lo susodicho haya habido o de presente haya havido entre la dicha ciudad de Zamora y vos la dicha. villa de San Miguel de la Rivera; y la ley que diz que las cartas. dadas contra ley, fuero o derecho deben ser obedecidas y no cumplidas; y que los fueros y derechos valederos no pueden ser derogados, salvo por Cortes. $\mathbf{E}$ otrosí no embargante qualesquier usos e costumbres que digan y aleguen y otras qualesquier leyes, fueros: e derechos é ordenanzas, premáticas senciones, estilos usados y acostumbrados y no usados, escritos y no escritos y qualesquier ordenanzas y escrituras de la dicha ciudad de Zamora y la Justicia della tengan que dispongan cerca de la dicha jurisdicion de essa dicha villa con qualquier firmezas, clausulas derogatorias y otras firmezas y no obstancias y otras qualesquier cosas de qualquier natura, effecto, vigor y calidad e misterio que lo embarguen o embargar pueda, aunque en ellas se oviesse de hacer expresa mencion y obiessen de ir expresadas de palabra o palabra en esta nuestra carta. Con las quales y cada una dellas y otra qualquier cosa que a esta merced que vos facemos pudiesse parar perjuicio de nuestro propio motu y cierta ciencia y poderío real absoluto de que en esta parte queremos usar y usamos haviendolas aquí por insertas e incorporadas dispensamos y las abrogamos y derogamos en quanto a esto toca e atañe e atañer pueda en qualquier manera quedando en su fuerza y vigor para en todas las otras cosas y si necesario es para más validación e corroboración é firmeza de esta nuestra merced ponemos perpetuo silencio para agora y para siempre jamás entre vos la dicha villa de San Miguel de la Rivera y la dicha ciudad de Zamora y sus aldeas para que sobre la dicha juridicion no vos puedan pedir ni demandar en ningún tiempo cosa alguna. $\mathrm{E}$ si desto que dicho es vos 
el dicho Concejo, alcaldes y regidores, escuderos, oficiales y homes buenos de la dicha villa de San Miguel de la Rivera quisiéredes nuestra carta de previlegio y confirmacion, mandamos a los nuestros Concertadores y Escribanos mayores de los nuestros previlegios y confirmaciones y otros oficiales que estan a la tabla de los nuestros sellos que vos la den e fagan dar la mas firme y bastante que les pidiéredes y menester oviérades cada e quando que por vos les fuere pedida y vos la pasen y sellen sin embargo ni contrario alguno. $\mathrm{Y}$ por que lo susodicho venga a noticia de todos y ninguno pueda pretender ignorancia, mandamos que esta nuestra carta de merced sea pregonada públicamente por pregón público ante escribano por las plazas públicas de essa dicha villa de San Miguel de la Rivera y de las otras villas y lugares que necesario sea. $Y$ mandamos que tome la razon della Hernando Ochoa mi Contador para hacer cargo a Fernando López del Campo, nuestro factor general, de los dichos un quento y ciento y setenta mil maravedís. Y los unos ni los otros no fagades ni fagan ende al que por alguna manera so pena de la nuestra merced y de cien mil maravedís para la nuestra Cámara a cada uno por quien fincare de lo anssí hacer y cumplir y demás mandamos al home que les esta nuestra carta de previlegio o el traslado della signado mostrare, que los emplace que parezcan ante nos en la nuestra Corte doquier que nos seamos del día que los emplazare hasta quince dias primeros siguientes so la dicha pena, so la qual mandamos a qualquier escrivano público para que esto fuere llamado que dende al que vos la mostrare dé testimonio con su signo por que nos sepamos en como se cumple nuestro mandado; y desto vos mandamos dar esta nuestra carta excripta en pergamino de cuero y sellada con nuestro sello de plomo pendiente en filos de seda a colores y firmada de la Sereníssima Princesa de Portugal Gobernadora de estos nuestros Reynos durante mi ausencia dellos, y refrendada de Juan Vázquez de Molina nuestro Secretario y librada de los del nuestro Consejo de la Hacienda. Dada en la villa de Valladolid a nueve del mes de Octubre del año del nascimiento de nuestro Salvador Jesuchristo de mil é quinientos é cinquenta y ocho años. La Princesa.

Tomóse la razon desta carta de venta y esencion en los libros de la razón que se tiene de la Hacienda de su Magestad en ausencia del Contador Hernando Ochoa por mí Joan de Galdos en Valladolid a trece de Octubre de mil é quinientos é cinquenta y ocho años. Juan de Galdos. El Licenciado Ignacio de Muñatones. El Doctor Velasco. El Lizenciado Valderrama.

(Archivo Histórico Nacional.-Clero. Zamora. Monasterio de San Benito. Leg. 173. Copia simple del siglo xvח.) 